\title{
Characterization analysis of raw and pyrolyzed plane tree seed (Platanus orientalis L.) samples for its application in carbon capture and storage (CCS) technology
}

\author{
Bojan Janković ${ }^{1}$ Vladimir Dodevski ${ }^{2} \cdot$ Marija Stojmenović ${ }^{2} \cdot$ Sanja Krstić ${ }^{2} \cdot J_{a s m i n a ~ P o p o v i c ́}{ }^{3}$
}

Received: 1 July 2017 / Accepted: 14 March 2018/Published online: 23 March 2018

(C) Akadémiai Kiadó, Budapest, Hungary 2018

\begin{abstract}
Raw and pyrolyzed samples of the plane tree seeds (PTS) were tested by various advanced analytical techniques including simultaneous TG-DSC technique, FTIR analysis, X-ray diffraction (XRD) analysis, Raman spectroscopy analysis, GC-MS (gas chromatography-mass spectrometry) analysis and scanning electron microscope analysis, for its characterization procedure and the pre-treatments in possible application in CCS. Nondestructive analytical method (XRD) showed that raw material is typical for carbon-rich material, where was identified increase in interlayer spacing within graphite structure. The XRD results of pyrolyzed sample at $850{ }^{\circ} \mathrm{C}$ showed a sudden loss in interlayer spacing. Spectroscopic analyses of pyrolyzed sample demonstrated the presence of typical aromatic structures found in amorphous carbon. Results indicate the high levels of the growth in basal planes of graphite structure in pyrolyzed sample. It was established that integrated reaction model parameters for pyrolysis of untreated PTS sample realistically describe active temperature period required for charcoal forming, under non-isothermal conditions. It was found that mechanical treatment of material results in increase in the number of chemical compounds. Micrograph showed the presence of variety of shapes and structures, where after pyrolysis, some dissipated pores were detected. One of these pores was partially blocked in some places, depending on the size of surface area. The results showed that the resulting char has very good features for further activation process, while the PTS would represent a good candidate in its application in the CCS.
\end{abstract}

Keywords Plane tree seed (PTS) - Characterization analytical techniques · Pyrolysis · Carbon structures · Exothermic phenomena

\section{Introduction}

Carbon dioxide $\left(\mathrm{CO}_{2}\right)$ emissions from power plants and factories are among the biggest contributors to global warming. Technologies for capturing $\mathrm{CO}_{2}$ from gas

Bojan Janković

bojanjan@ffh.bg.ac.rs

1 Department of General and Physical Chemistry, Faculty of Physical Chemistry, University of Belgrade, Studentski trg 12-16, P. O. Box 137, Belgrade 11001, Serbia

2 Laboratory for Materials Sciences, Institute of Nuclear Sciences "Vinča", University of Belgrade, Mike Petrovića Alasa 12-14, P.O. Box 522, Belgrade 11000, Serbia

3 Department of Chemical and Mechanical Wood Processing, Faculty of Forestry, University of Belgrade, Kneza Višeslava 1, Belgrade 11030, Serbia streams have been used for many years to produce a pure stream of $\mathrm{CO}_{2}$ from natural gas or industrial processing for use in food processing and chemical industries. Both postcombustion $\mathrm{CO}_{2}$ capture [1,2] and oxy-combustion [3] technology provide retrofit options for existing coal-fired power plants. Methods currently used or developed for $\mathrm{CO}_{2}$ separation include but not limited to the following issues: Physical and chemical solvents, particularly monoethanolamine (MEA) $[4,5]$, various types of membranes [6, 7], adsorption onto solids [4, 8, 9], cryogenic separation [10] and other novel technologies, include ionic liquids [11], nanoparticle organic hybrid materials [12] and chemical looping sorbents [13, 14]. The mentioned methods can be used on a range of industrial processes; however, their use for removing $\mathrm{CO}_{2}$ from high-volume, low$\mathrm{CO}_{2}$ concentration flue gases, such as those produced by coal-fired power plants, is more problematic. The high 
capital costs for installing post-combustion separation systems to process the large volume of flue gas are a major impediment to post-combustion capture of $\mathrm{CO}_{2}$.

Significance of $\mathrm{CO}_{2}$ emission reduction was also discussed at the world level, if we take into account the 2015 United Nations Climate Change Conference, COP 21, which is held in Paris [15].

The purpose of the meeting was that the carbon dioxide emissions should be zero by 2070 in order to prevent climate disasters. In December, after two decades of tense climate negotiations, representatives of nearly 200 countries have reached a milestone on the road to that goal. By the Paris Agreement, which clearly signals the transition from fossil fuels to renewable energy sources, governments will be responsible for the urgent objectives of greenhouse gas emissions. The meeting was commended for the longterm goal of achieving net gas emissions to zero in the second half of the century.

A number of integrated carbon capture technologies are designed and built around existing or new energy conversion systems. The past experience shows that proposed power plant with carbon capture would have substantially lower greenhouse gas emissions and somewhat higher emissions of acid precursors than a gas-fired power plant without carbon dioxide capture and storage (CCS).

Carbonaceous materials such as activated carbons are attractive as $\mathrm{CO}_{2}$ adsorbent $[16,17]$ due to its wide availability, the high thermal stability, low cost, good chemical resistance, ease of preparation and the control of pore structure, low regeneration energy and low sensitivity to water due to its hydrophobicity properties. Activated carbons in the form of granules, extrudates, powders, fibers or beads can be produced from suitable thermosetting precursors by either thermal or chemical routes. The common commercial feedstocks include biomass material such as wood, coconut shell and fruit pits, and fossilized plant matter such as peats, lignites and all ranks of coal. Namely, the various materials precursors were used in order to obtain the porous carbons for $\mathrm{CO}_{2}$ capture [18-21].

The main objective of this work is the application of the plane tree seeds (Platanus orientalis L.) as biomass source in order to obtain activated carbons (AC) as a promising future project for use in CCS. Forests and other green areas as living organisms that photosynthesize absorb the free $\mathrm{CO}_{2}$ in atmosphere, stabilize them in more stable complex compounds and contribute to their long-term storage. For this purpose, one of the most important strategies for global warming and climate change in developed countries is to store $\mathrm{CO}_{2}$ in the forest ecosystem (plant, dead cover and soil). This strategy is generally described as carbon sequestration. Urban trees and urban forests have an important position in order to sequestration $\mathrm{CO}_{2}$ in the city centers [22]. Two tree species, Platanus orientalis L. and black poplar (Populus nigra), store a very high mass of carbon compared to their frequency in the population, storing $4 \%$ each of the total carbon stored while only representing 0.1 and $0.3 \%$ of the tree population, respectively [23]. Urban trees reduce atmospheric carbon dioxide $\left(\mathrm{CO}_{2}\right)$ in two ways: directly-trees absorb and sequester $\mathrm{CO}_{2}$ - and indirectly - trees lower the demand for heating and air conditioning, thereby avoiding the emissions associated with electric power generation and natural gas consumption.

The aim of this paper is to select the experimental techniques for characterization analysis of the raw and pyrolyzed samples of the plane tree seeds (PTS) (Platanus orientalis L.) and assessment of the results in order to obtain a potential solid sorbent for a sorption processes of the harmful gases such as $\mathrm{CO}_{2}$. The paper provides an insight into the results of pyrolyzed product at high temperatures which would be used as an adsorber for gases, where applied experimental techniques serve for purpose of its characterization, primarily obtained by the pyrolysis process of the "fruit" parts of Platanus orientalis L. tree. The actual material was selected because we estimated that the pyrolyzed product would have good predispositions for use in CCS and also that the literature data related to this biomass precursor in obtaining carbon black are very scarce.

The following techniques have been used in this paper to characterize the crude precursor and pyrolyzed product: (a) Static pyrolysis process (monitored at high fixed operating temperature with an static heating regime of the precursor material) was conducted in a horizontal tube reactor, where the measurement was taken in order to obtain larger quantities of carbon for commercial purposes and for further analysis required by other experimental techniques, (b) the pyrolysis process was carried out in the TG-DSC device for the purpose of thermal testing of the sample to identify the appropriate transformations that the material suffers during the process in an inert atmosphere, and to detect the various heat phenomena on the laboratory-scale grade (the purpose of this measuring was not to examine the various experimental factors on the studied process, such as the different particle size of the sample, the influence of the variation of the heating rate, the effect of changing the flow rate of the carrier gas, the influence of the variation in the initial mass of the sample and the influence of the partial water vapor pressure); also, the TG technique was frequently used for the evaluation of solid sorbents for $\mathrm{CO}_{2}$ capture [24, 25], (c) Fourier transform infrared (FTIR) spectroscopy was used in order to obtain the information about the activity of active chemical functional groups and to have an insight into how $\mathrm{CO}_{2}$ could interact with them; (d) the Raman spectroscopy of 
the pyrolyzed sample was used primarily to characterize the char structure and is fundamentally important for the clean utilization of applied biomass precursor, (e) X-ray diffraction (XRD) analysis was used in order to obtain information about spatial structures of the raw material and the obtained char at elevated temperatures, (f) GC-MS [gas chromatography (GC)-mass spectrometry (MS)] analysis was used in the characterization procedure of the organic compounds which contain the raw material and to characterizes the volatile pyrolysis products, since most of thermal degradation that results from free radical reactions was initiated by bond breaking, and depends on the relative strengths of the bonds that hold molecules together. This analysis allows us to get information about organic matter contents comprises the chemical families capable for trapping the $\mathrm{CO}_{2}$ molecules; $(\mathrm{g})$ the scanning electron microscope (SEM) was used to evaluate the structural variations in char particles after thermal treatment.

It should be noted that actual work also describes the possibility of utilizing plane tree seeds (PTS) by-product as biofuels by producing char via pyrolysis. Therefore, the presented results should be viewed from two perspectives: The obtained char can be used as a solid fuel or as a precursor in the activated carbon production.

\section{Experimental}

\section{Material}

The material used in our study was harvested from single trees of plane tree (Platanus orientalis L.) growing in the Belgrade parks (Serbia) in September month. The plane tree seed diameter was about $2-3 \mathrm{~cm}$. Achenes with their thin bristle fibers were used for experimental work. Their length was up to $1 \mathrm{~cm}$ and about $1 \mathrm{~mm}$ thick, while bristles were shorter and a few times thinner.

Regarding the number of replicates, it should be pointed out that we had taken technical replicate measurements. In all cases, for the data from the three replicate measurements of each type to assess the statistical significance of the difference in the signal responses of the tested sample, we found $p>0.05$ (assuming a Gaussian distribution), indicating that they are not significantly different, what was provided unarguable confirmation of sample replicates performance in comparison with the results.

\section{Pyrolysis in a horizontal tube reactor}

The raw plane tree seed (PTS) was first peeled off and washed with water to remove dirt and then dried at $T=80^{\circ} \mathrm{C}$ for $24 \mathrm{~h}$ in an oven (Carbolite Gero $\mathrm{GmbH} \&$ Co. KG, Hesselbachstraße 15, 75242 Neuhausen,
Germany) to reduce the moisture content. The dried PTS was then ground (using Planetary Micro Mill Pulverisette 7, Fritsch, Industriestrasse 855743 Idar-Oberstein, Germany) and sieved (Vibratory Sieve Shaker AS 200 basic (0.5-1.5 mesh), Retsch, Retsch-Allee 1-5, 42781 Haan, Germany). Particle size fractions in a range of the $0.5-1.5 \mathrm{~mm}$ were used for pyrolysis experiment.

The pyrolysis was carried out in a stainless steel horizontal tube reactor with open plate pellets (Protherm Furnaces, model PTF 16/38/250, Turkey). About $20 \mathrm{~g}$ of materials was placed in a horizontal tube reactor. During the pyrolysis process, the purified nitrogen $\left(\mathrm{N}_{2}\right)$ at a flow rate of $\varphi=500 \mathrm{~cm}^{3} \mathrm{~min}^{-1}$ was used as purge gas. The reactor temperature was increased from the room temperature up to desired operating (static) temperature of $850{ }^{\circ} \mathrm{C}$. When operating (working) temperature reached the desired value, it was held for $1 \mathrm{~h}$. At the end of pyrolysis, the gaseous flow of $\mathrm{N}_{2}$ in a reactor was maintained during the cooling until the room temperature. The heating rate mode was constant and was amounted $\beta=4{ }^{\circ} \mathrm{C} \min ^{-1}$.

\section{Proximate, ultimate and chemical ingredients analyses}

The ultimate analysis was carried out on the LECO elemental analyzer, model CHN 628 (LECO Corporation, St. Joseph, Michigan, USA). The instrument range for carbon content is from $0.02 \mathrm{mg}$ up to $175 \mathrm{mg}$, hydrogen content from $0.1 \mathrm{mg}$ up to $12 \mathrm{mg}$ and nitrogen content from $0.04 \mathrm{mg}$ up to $50 \mathrm{mg}$, respectively. Precision ranges of the instrument are the follows: carbon $(0.01 \mathrm{mg})$, hydrogen $(0.05 \mathrm{mg})$ and nitrogen $(0.02 \mathrm{mg})$. Helium $(99.995 \%)$ was used as a carrier gas, while samples were combusted in a stream of the pure oxygen (99.995\%). Prior to each measurement, the calibration checking was verified with certified reference material as ethylenediaminetetraacetic acid (EDTA). Both calorific and elemental analyses were performed in certified laboratory and with compliance of all requirements presented in ASTM D5373 [26].

Determination of the higher heating value (HHV) was carried out on the device IKA, model C200 $\left(\mathrm{IKA}^{\circledR}\right.$ Werke GmbH \& Co. KG, Janke \& Kunkel-Str. 1079219 Staufen, Germany/Deutschland). Samples were prepared by grinding to the granulation below 200 microns. The moisture content of the sample is equal to the equilibrium moisture, i.e., sample is brought into a state of equilibrium with a moisture content in the laboratory. Moisture content was determined before each measurement in a calorimeter. Measurements were taken in isoperibol mode. For starting procedure, the floss known calorific value was used and the unity will automatically subtract from the measured values. One end of the ignition wire is connected to the carrier 
through which the sample is passed during the ignition current, and the other hand was immersed in the sample. In order to achieve complete combustion, the bomb calorimeter is filled with oxygen (99.5\%) to a pressure of 30 bars. Before each measurement, the inspection of the device with the help of a certified tablet sample-benzoic acid-was carried out (also known as the thermal power). Measurements have been taken with double repetitions in which the criteria are achieved and where repeatability of measurements was prescribed in accordance with ISO 1928 [27]. The lower heating value (LHV) is calculated from the measured values of the upper thermal power and elemental composition of the fuel, according to ISO 1928 [27]. The sample weight was about $0.5 \mathrm{~g}$.

After sieving, in accordance with the TAPPI standard method (T $257 \mathrm{~cm}-12$ ) [28], the raw material with particle dimension of $0.5-1 \mathrm{~mm}$ was taken for the compositional analysis. The moisture content of the samples was determined gravimetrically according to TAPPI standard method T $264 \mathrm{~cm}-97$ [29]. The content of cellulose in the samples was determined by the Kürschner-Hoffer method [30]. The lignin content after extraction (toluene-ethanol) was determined by the Klason method [31], with a spectrophotometric determination (Specord $^{\circledR}$ Plus UV/Vis Spectrophotometer, Analytik Jena AG, Analytical Instrumentation Konrad-Zuse-Str. 1, 07745 Jena, Germany) of acid-soluble lignin (based on absorption of ultraviolet radiation, with most often used wavelength of $205 \mathrm{~nm}$ ) according to TAPPI method T UM 250 [32]. For the determination of extractives soluble in organic solvents, the TAPPI standard method T $264 \mathrm{~cm}-97$ was used. In actual case, a mixture of toluene and methanol in a volume ratio of 1:2 $\left(\mathrm{C}_{6} \mathrm{H}_{5} \mathrm{CH}_{3} / \mathrm{C}_{2} \mathrm{H}_{5} \mathrm{OH}=2 / 1\right.$, v/v $)$ was used. The content of extractives soluble in hot water is determined according to TAPPI standard method $\mathrm{T} 207 \mathrm{~cm}-99$ [33] and mineral content through the ash, according to the standard method ASTM D1102-84 [34]. The content of hemicellulose is determined approximately, as a complement to the content of certain components up to $100 \%$. The results are expressed in relation to the absolute dry weight of the studied material and presented as the mean (arithmetic mean) for four repeated measurements.

\section{Pyrolysis of the raw material in a commercial device for thermal analysis}

The pyrolysis process of the raw sample was carried out on a simultaneous TG-DSC device for thermal analysis testing (SETSYS Evolution, Setaram, France). The single measurement at the heating rate of $10{ }^{\circ} \mathrm{C} \min ^{-1}$ was taken in alumina $(100 \mu \mathrm{L})$ crucibles, under inert atmosphere [nitrogen $\left(\mathrm{N}_{2}\right)$ atmosphere with flow of carrier gas which was $\left.\varphi=20 \mathrm{~mL} \mathrm{~min}{ }^{-1}\right]$. The actual heating rate was chosen that not to be too low $\left(2\right.$ or $\left.5{ }^{\circ} \mathrm{C} \mathrm{min}^{-1}\right)$ or too high (beyond $20{ }^{\circ} \mathrm{C} \mathrm{min}^{-1}$ ) to avoid effects of the thermal lag which may arise from different factors such as characteristics of the experiments and influence of the Arrhenius parameters changing associated with the experimental data [35]. It has been shown that the heating rate of $\beta=10^{\circ} \mathrm{C} \min ^{-1}$ is the most optimal for performing a thermo-analytical test for the studied system. On the other hand, there are no recordings at multiple values of the heating rates, either for the purpose of influencing the various experimental fatigues associated with the sample itself (such as particle size and variation in the initial mass of the sample used in the experiments) or for the kinetic analysis of the pyrolysis process.

Before introducing an inert atmosphere, working environment was evacuated up to $10^{-2} \mathrm{mbar}(1 \mathrm{~Pa})$. TG resolution was $0.1 \mu \mathrm{g}$. Both TG and DSC measurements were taken through the single recording with a operative mass sample of $5.0 \pm 0.1 \mathrm{mg}$, in the experimental temperature range of $\Delta T=40-810^{\circ} \mathrm{C}$. All TG and DSC results in this study were corrected by baseline which obtained from the runs with empty alumina crucible, under the same conditions to eliminate the experimental system errors.

\section{FTIR analysis}

The surface functional groups and structure of the raw material were studied by the Fourier transform infrared spectroscopy (FTIR). The FTIR spectrum of the raw material was collected using a PerkinElmer Spectrum two FTIR spectrometer (PerkinElmer, Inc., Waltham, Massachusetts, USA) in transmission mode. Sample for measurement was prepared using the pressed $\mathrm{KBr}$ pellets (1:100) technique. The spectrum was recorded in the range from 4000 to $400 \mathrm{~cm}^{-1}$ with the resolution mode of $4 \mathrm{~cm}^{-1}$, in order to obtain the spectrum lines.

\section{The X-ray diffraction (XRD) analysis}

The raw and pyrolyzed samples were characterized by the X-ray powder diffraction (XRPD) analysis using Ultima IV Rigaku (Rigaku Corporation 3-9-12, Matsubara-cho, Akishima-shi, Tokyo 196-8666, Japan) diffractometer, equipped with the $\mathrm{Cu} \mathrm{K} \alpha 1,2$ radiation source (a generator voltage of $40.0 \mathrm{kV}$ and a generator current of $40.0 \mathrm{~mA}$ ). All samples were recorded in the range of $5-80^{\circ} 2 \theta$, with a scanning step size of $0.02^{\circ}$ and at a scan rate of $2^{\circ} \mathrm{min}^{-1}$.

\section{The Raman spectroscopy analysis of a sample after pyrolysis process}

The Raman spectrum of the pyrolyzed sample was collected on a DXR Raman microscope (Thermo Scientific, 
USA) equipped with an Olympus optical microscope and a CCD detector, with a diode-pumped solid-state highbrightness laser $(532 \mathrm{~nm})$ and a $10 \times$ objective. The pyrolyzed sample after cooling was placed on $X-Y$ motorized sample stage. The analysis of the scattered light was carried out by the spectrograph with a grating 900 lines $\mathrm{mm}^{-1}$. The laser power was $1 \mathrm{~mW}$.

The Raman spectrum in the range between 800 and $1800 \mathrm{~cm}^{-1}$ was deconvoluted using a commercial "PeakFIT" program. The linear baseline and Gaussian shape (Gaussian Amp function) were used to describe the individual Raman bands.

\section{GC-MS (gas chromatography-mass spectrometry) analysis}

The GC-MS analysis was performed on the raw and pyrolyzed plane tree seed (PTS) samples. The PTS samples for measurements are delivered in a plastic bag. About $1 \mathrm{~g}$ of the sample was measured and transferred in glass vial for extraction. Extraction process was held in ultrasonic bath for $30 \mathrm{~min}$ at the room temperature with the addition of $5 \mathrm{~mL}$ of the methanol, which is extraction solvent. Analytes dissolved in methanol were separated from the sludge by putting it through the membrane filter. Then, the $1 \mathrm{~mL}$ of filtrate was taken for the analysis by the GC-MS method.

The qualitative analysis of the compounds in the tested sample was performed with the gas chromatograph TRA$\mathrm{CE}^{\mathrm{TM}} 1300$ Thermo Fisher Scientific (Thermo Fisher Scientific Co., Waltham, Massachusetts, USA) which separates different analytes in a mixture by chromatograph column DB5, HP5, $30 \mathrm{~m} \times 0.25 \mathrm{~mm}$ i.d., film $0.25 \mu \mathrm{m}$, Trace Gold TG-5MSGC (Thermo Scientific ${ }^{\mathrm{TM}}$ TraceGOLD, Thermo Fisher Scientific Co., Waltham, Massachusetts, USA). The column temperature mode starts with initial temperature of $40{ }^{\circ} \mathrm{C}$ during $4 \mathrm{~min}$; then, the temperature was increased at $T=280{ }^{\circ} \mathrm{C}$, with an increments of $10{ }^{\circ} \mathrm{C} \mathrm{min}{ }^{-1}$, and at $T=280{ }^{\circ} \mathrm{C}$, it was held until $42 \mathrm{~min}$. The injected volume was $3 \mu \mathrm{L}$ with autosampler AI 1310 (Thermo Scientific ${ }^{\text {TM }}$ AI/AS 1310 Series Autosampler, Thermo Fisher Scientific Co., Waltham, Massachusetts, USA). The detection was carried out with Thermo Scientific ISQ LT single quadrupole mass detector (ISQ $^{\mathrm{TM}}$ Series, Thermo Fisher Scientific Co., Waltham, Massachusetts, USA) in a 1.2-1100 u mass range. The data processing was performed in software with the commercial name Xcalibur 2.2. SP1, which includes the library data search.

Spectroscopic methods as well as the chemical analyses such as GC-MS generate huge amounts of data, and the numbers of observations are far smaller than the number of variables, where the observations correspond to the samples and the variables correspond to (for example) all of the data points in their spectra. Multivariate data analysis (MDA) makes it possible to extract meaningful information from such data. Principal component analysis (PCA) can be used to obtain an overview of the data, determine which observations deviate from the others, and analyze the relationships among observations. The groupings identified in an initial PCA can be used to classify new samples and identify samples that do not fit into the established groupings, which may merit further investigation.

\section{SEM analysis}

The morphology of raw and pyrolyzed samples was observed using the scanning electron microscope (SEM) JEOL JSM-5800 (JEOL, Ltd., Akishima, Tokyo, Japan). The tested sample was placed in a carbon strip (which is sticky on the both sides-on one of the sticky sides with tweezers, the pulverized sample was placed), which is then entered (with side where the sample was not submitted) to the carrier of the device, and then carries out the corresponding measurement.

\section{The integral reaction heats correlated with experimental temperatures during pyrolysis}

The biomass pyrolysis mass loss can be classified into three stages: the moisture removal in the first stage, organic content removal in the second stage in which different kinds of hemicelluloses and cellulose composited and in the last stage, the fixed carbon content decomposition may occur. The heat released or required $\Delta Q(\mathrm{~J})$ to any experimental temperature $T$ from the basic temperature $\left(T^{*}\right)$ can be expressed as [36]:

$\Delta Q=Q-Q^{*}=\int_{t^{*}}^{t} q \mathrm{~d} t$,

where $q$ is the original heat flow at time $t$ measured by DSC. The corresponding integral reaction heat $H\left(\mathrm{~J} \mathrm{~g}^{-1}\right)$ to any experimental temperature is $H=\left(Q-Q^{*}\right) /\left(m^{*}-m\right)$, where $Q$ and $Q^{*}$ are the residual heat evolved at the actual temperature $T$ and time $t$, and the heat evolved at the start time $\left(t^{*}\right)$ of decomposition, respectively; $m$ and $m^{*}$ are the residue and the basic sample masses at the temperatures $T$ and $T^{*}$, respectively. DSC signal is influenced by the baseline excursion of the apparatus, so it should be corrected in advance. The heat $H_{\mathrm{r}}\left(\mathrm{J} \mathrm{g}^{-1}\right)$ released for biomass pyrolysis can be presented as $H_{r}=\left(Q-Q^{*}\right) / m$. Further, in order to correlate the integral reaction heats with temperature, it was assumed that the monitored reaction is a 
function of the reaction temperature and appropriate numerically derived parameters, which connect (from physical aspects) the reaction heat with temperature of a given reaction. This method requires setting the appropriate interpolation equation for each thermal transformation.

\section{Results and discussion}

\section{The ultimate/proximate results}

Table 1 presents the results of ultimate and proximate analyses of the plane tree seed (Platanus orientalis L.) samples together with HHV and LHV values, respectively.

Analysis findings show that wood precursor has acceptable heating values compared with wood and its products [37], but much elevated heating values compared to agricultural wastes [38]. Also, the observed raw material contains the high content of carbon and hydrogen (Table 1).

In addition, the ash content is not so great, if we make a comparison with palm of Phoenix dactylifera L. [39], palm leaflets [38] or sugarcane [40]. However, the resulting ash content is not negligible, bearing in mind that high-ash content biomass functions as a precursor to form highporosity carbons, which can be obtained from wood materials. Also, it can be observed that tested sample represents the carbon-rich sample $(\mathrm{C}(\%)=47.760$, Table 1). In addition, the combination of rather high oxygen content $(\mathrm{O}(\%)=40.329$, Table 1$)$ (which is here larger than the one present in Platanus orientalis leaves, $\mathrm{O}$
$(\%)=33.700 \%$ [41]) and high organic volatile matter in biomass sample may indicate the potential for creating the large amounts of inorganic vapors in combustible processes. Also, the content of oxygen in starting material is an essential for the subsequent activation process (by the $\mathrm{CO}_{2}$ sorption process) of obtained carbons by pyrolysis, because during activation, the decrease in oxygen fraction may occur by identifying the intensification of $\mathrm{C}-\mathrm{CO}_{2}$ reaction.

The fairly high values of HHV and LHV were identified, and obtained values are very close to the values obtained for Macadamia nut shells $\left(\mathrm{HHV}=20714 \mathrm{~kJ} \mathrm{~kg}^{-1}\right)$ and Cypress wood chips $\left(\mathrm{LHV}=18727 \mathrm{~kJ} \mathrm{~kg}^{-1}\right)$ which are also rich in the carbon, but these values are less than those identified for bituminous coal (HHV $=27061 \mathrm{~kJ} \mathrm{~kg}^{-1}$ and $\mathrm{LHV}=24856 \mathrm{~kJ} \mathrm{~kg}^{-1}$ ) [42]. Content of cellulose (which is basic building blocks of the cell wall of plants) amounts $33.790 \%$ (Table 1), which is a low value, probably because it is a "fruit" of the plant.

For oriental plane tree (Platanus orientalis L.), Rowell et al. [43] state the cellulose content of $44.0 \%$, without specifying that it is a date for "fruit" of the plant. In contrast, the total lignin content of $25.890 \%$ (Table 1) is slightly higher than for the Klason lignin content, which amounts $21.000 \%$ for oriental plane tree. Contents of extractives dissolved by the hot water and in a mixture of toluene/ethanol (results amount 9.680 and $7.120 \%$, respectively (Table 1)) are high, probably because the tested material comes from the physiologically active parts of the plant.
Table 1 Ultimate and proximate analysis results of plane tree seed (Platanus orientalis L.) samples with HHV and LHV values, respectively

\begin{tabular}{ll}
\hline Ultimate and proximate analyses $^{\mathrm{a}}(\%)$ & \\
\hline Moisture & $9.430 \pm 0.129$ \\
Ash & $3.610 \pm 0.458$ \\
Content of extractives in hot water & $9.680 \pm 0.750$ \\
Content of extractives in a mixture of toluene/ethanol & $7.120 \pm 0.305$ \\
Nitrogen & $1.685 \pm 0.005$ \\
Carbon & $47.760 \pm 0.101$ \\
Oxygen & \\
Hydrogen & $40.329 \pm 0.150$ \\
\hline Lignocellulosic composition $^{\mathrm{a}}$ & $6.616 \pm 0.208$ \\
\hline Cellulose/\% & $33.790 \pm 0.629$ \\
Hemicellulose (difference to 100\%)/\% & 19.910 \\
Lignin/\% & $25.890 \pm 1.837$ \\
HHV/kJ kg & \\
LHV/kJ kg & \\
\hline
\end{tabular}

${ }^{a}$ The results are expressed in relation to the absolute dry weight of material

${ }^{\mathrm{b}}$ Content of oxygen is calculated by using the formula: $\mathrm{O} / \%=100 / \%-\mathrm{Ash} / \%-\mathrm{C} / \%-\mathrm{N} / \%-\mathrm{H} / \%$ 


\section{FTIR results}

Figure 1 shows the FTIR spectrum of Platanus orientalis L. sample, with designated all characteristic vibrational bands. The broad absorption peak at $\sim 3420 \mathrm{~cm}^{-1}$ observed in actual spectrum is due to hydrogen bonded $\mathrm{O}-\mathrm{H}$ stretching vibration of hydroxyl groups. Theoretically, hydroxyl bond should have weakened as dehydration of monosaccharide present in wood material proceeded during the thermal conversion. The sharp absorption bands at $\sim 2926 \mathrm{~cm}^{-1}$ and $\sim 2852 \mathrm{~cm}^{-1}$ are attributed to asymmetric and symmetric stretching vibrations of methylene $(\mathrm{C}-\mathrm{H})$ groups. However, this band is much weaker than the same band in the annual fiber crops. The band at $\sim 1640 \mathrm{~cm}^{-1}$ in Platanus orientalis L. sample (Fig. 1) is good indicator for estimating the changes produced in hardwood and softwood, in either fresh or dried state. The occurrence of such band indicates that $\delta \mathrm{H}-\mathrm{O}-\mathrm{H}$ bending vibration arises from water molecules. Also, this band supports existence of $\mathrm{C}=\mathrm{C}$ vibrations, which is followed by the presence of aromatization of sugars structure.

In addition, the observed peak at $\sim 1243 \mathrm{~cm}^{-1}$ (Fig. 1) may be attributed to vibrations of guaiacyl rings and stretching vibrations of $\mathrm{C}-\mathrm{O}$ bonds (which were observed in softwoods, as Platanus orientalis L.) [44]. The clearly observable band at $\sim 1115 \mathrm{~cm}^{-1}$ can be attributed to the aromatic $\mathrm{C}-\mathrm{H}$ in-plane deformation (typical for syringyl units) and also to the secondary alcohols or $\mathrm{C}=\mathrm{O}$ stretch typical for wood species. The band caused by $\mathrm{O}-\mathrm{H}$ out plane bending vibrations is located at the $\sim 674 \mathrm{~cm}^{-1}$ (Fig. 1) [45].

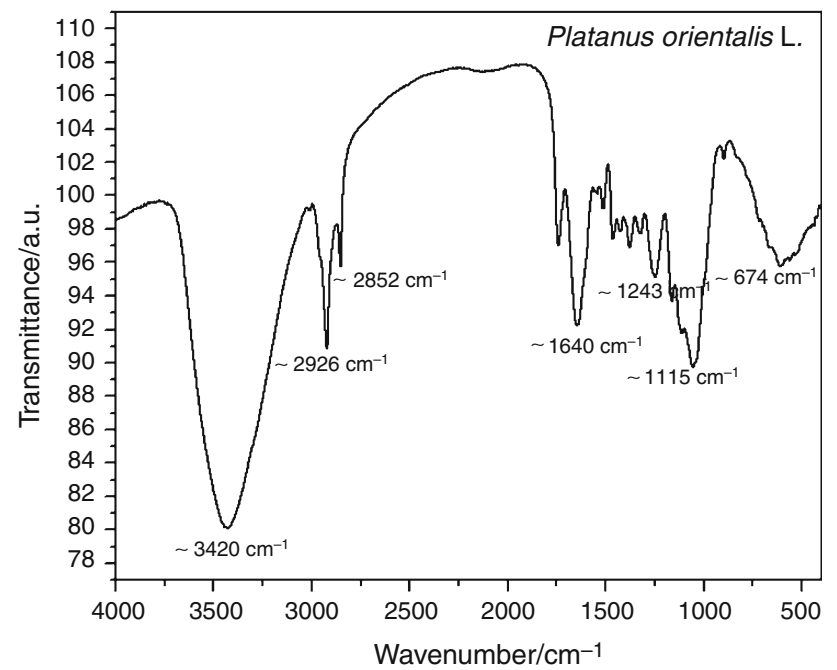

Fig. 1 FTIR spectrum of Platanus orientalis L. (Seed samples) with designated all characteristic vibrational bands

\section{XRD results}

Figure 2 shows the XRD patterns of the raw (the powderlike sample which is pulverized with particle size of $r_{\mathrm{m}}$ $=1200 \mu \mathrm{m}$ ) sample (a) and pyrolyzed (b) sample, where the pyrolyzing sample is monitored at the operational temperature of $850^{\circ} \mathrm{C}$.

From the XRD pattern of the raw sample (Fig. 2a), we may see the presence of the material with amorphous characteristics. We can notice emergence of two broad peaks with different intensities, which are positioned at around $2 \theta=10^{\circ}$ and $2 \theta=24^{\circ}$, respectively. The observed diffraction peaks (Fig. 2a) are typical for carbon-rich material, where peak at $2 \theta=10^{\circ}$ suggests the graphite structure. The second peak $\left(\sim 24^{\circ}\right)$ indicates the presence of (002) hexagonal graphitic plane. In both considered
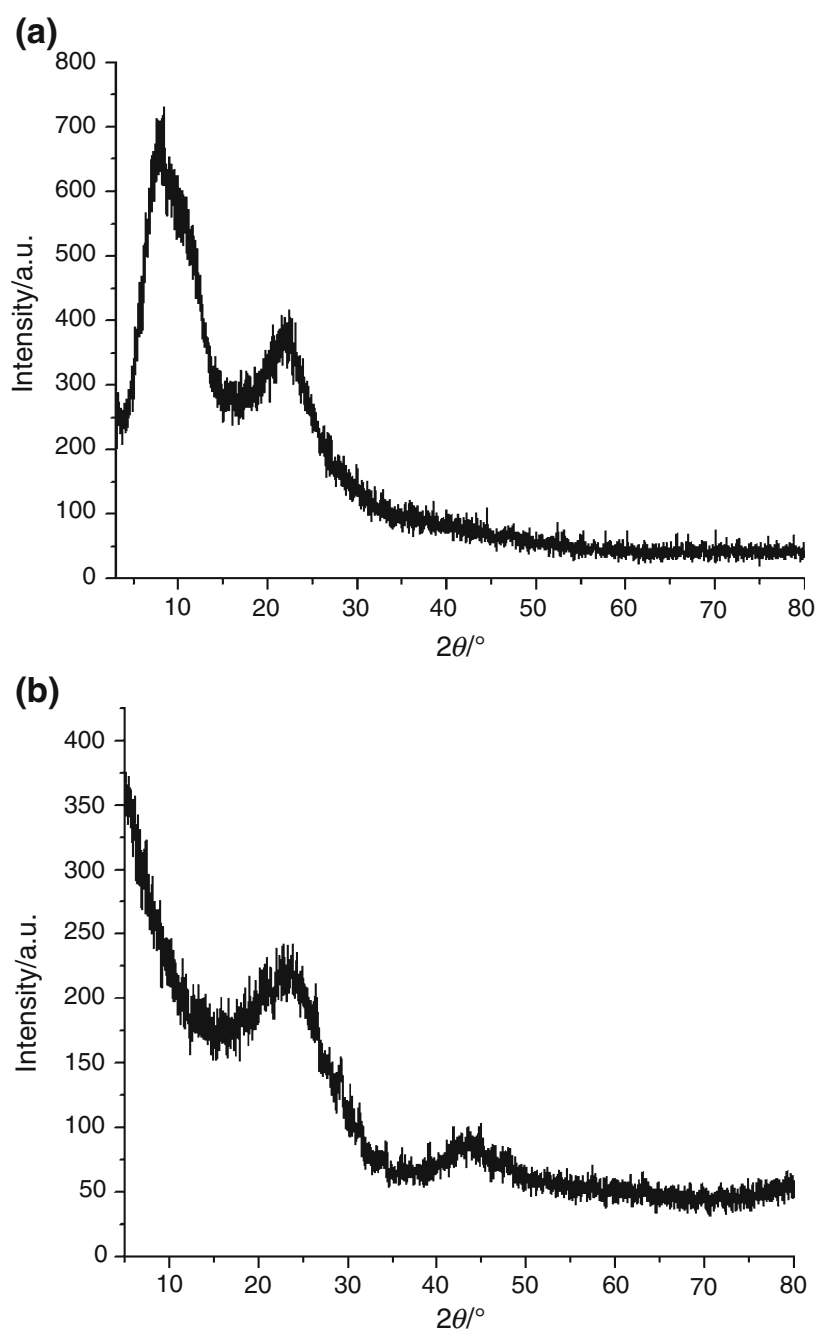

Fig. 2 XRD patterns of the raw (the powder-like sample which is pulverized) sample (a) and pyrolyzed (b) plane tree seeds, where the pyrolyzing sample is monitored at $850^{\circ} \mathrm{C}$ 
cases (Fig. 2a, b), the broad peak at around $2 \theta=24^{\circ}$ is an indication of an amorphous phase.

On the other hand, for the raw sample (Fig. 2a), there are several unindexed small peaks latched on to broad peak and continue to appear till the end of diffractogram. These peaks presumably correspond to the mineral oxides (such as $\mathrm{K}, \mathrm{Mg}, \mathrm{Pb}$ and $\mathrm{Ca}$ ) [46]. Comparing the raw sample diffractogram results (Fig. 2a) with FTIR spectrum (Fig. 1), the "graphite spectrum" contains the broad peak centered at $\sim 1640 \mathrm{~cm}^{-1}$ attached to water molecules, and this phenomena apparently does not exist in pyrolyzed sample at the high temperatures, because obviously diffraction patterns are not identical.

However, for pyrolyzed sample at $850{ }^{\circ} \mathrm{C}$, the diffraction peak at around $2 \theta=10^{\circ}$ is disappeared, because after pyrolysis, we have sudden loss in interlayer spacing. This probably indicates the collapse of structures into the graphite [47].

The pyrolysis temperature strongly affects on the changes in the carbon layer interspaces and also has an influence in organization/disorganization of the entire structure. In addition, for pyrolyzed sample (Fig. 2b), the broad peak at around $2 \theta=44.5^{\circ}$ can be assigned to turbostratic band of the disordered carbon material (100 direction) [48]. However, the peaks were not as sharp as that of pure carbon [49] and these results are direct evidence for the presence of carbon in all considered samples.

\section{TG-DSC results}

Figure 3 shows simultaneous TG-DSC curves for nonisothermal pyrolysis process of untreated plane tree seed sample (Platanus orientalis L.) at the heating rate of $\beta=10{ }^{\circ} \mathrm{C} \min ^{-1}$.

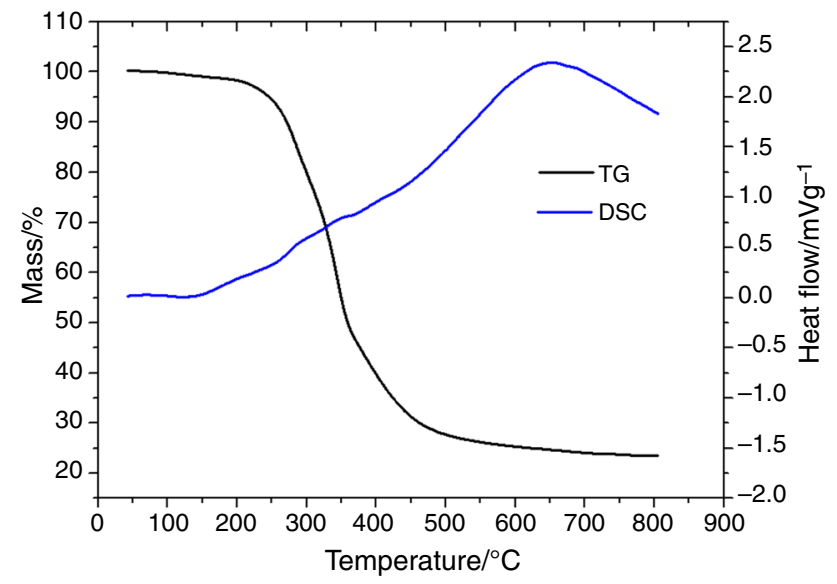

Fig. 3 Simultaneous TG-DSC curves for non-isothermal pyrolysis process of untreated plane tree seed sample (Platanus orientalis L.) at the heating rate of $10{ }^{\circ} \mathrm{C} \mathrm{min}^{-1}$
From TG curve (Fig. 3), it can be seen that mass loss of tested sample mainly occurs at three stages: $40-193{ }^{\circ} \mathrm{C}$ (mass loss $\Delta m_{\mathrm{I}}=2.06 \%$ ), $193-357.13{ }^{\circ} \mathrm{C}$ (mass loss $\Delta m_{\mathrm{II}}=47.45 \%$ ) and $357.13-800{ }^{\circ} \mathrm{C}$ (mass loss $\Delta m_{\mathrm{III}-}$ $=27.41 \%$ ), respectively. On the other hand, from DSC curve, we have identified one endothermic effect at temperature $T_{\text {endo }}=122.16{ }^{\circ} \mathrm{C}$ and two exothermic effects at temperatures $T_{\text {exo1 }}=325.03{ }^{\circ} \mathrm{C}$ and $T_{\text {exo2 }}=655.29{ }^{\circ} \mathrm{C}$, respectively. The first stage attached to $T_{\text {endo value char- }}$ acterized by mass loss decrease of $2.06 \%$ is due to the loss of water physically bound to the plane tree seed and desorption of strongly bound water inside the wood precursor fiber. (This applies particularly to temperatures above $100{ }^{\circ} \mathrm{C}$, where evaporation of water occurs, and which is followed with heat absorption from the system.) The second stage, attached to $T_{\text {exo1 }}$ value characterized by mass loss decrease of $47.45 \%$, can be attributed to devolatilization of present organic contents (including all pseudocomponents of biomass usually, through the chain scission reactions and breaking of some carboxyl, carbonyl bonds, etc., in a ring structure evolving $\mathrm{H}_{2} \mathrm{O}, \mathrm{CO}$ and $\mathrm{CO}_{2}$ ). The exothermic peak at $325.03{ }^{\circ} \mathrm{C}$ is typical for hemicelluloses decomposition in wood species [50, 51]. The lignin decomposition occurs in a much broader temperature interval of $250-550{ }^{\circ} \mathrm{C}$, but the minor decomposition can be observed already in the lower temperatures [52]. Consistent with previous fact, lignin does not present a specific maximum decomposition rate and, therefore, cannot be identified within a particular temperature range.

The part of present acids evaporate as a steam in the second stage. In addition, the exothermic phenomena begin above $270{ }^{\circ} \mathrm{C}$, so that the external heating is no longer needed, because the exothermic reaction generates heat. It can be pointed out that the decomposition of cellulose occurs in the temperature interval of $305-375^{\circ} \mathrm{C}$ which is also exothermic [51]. The share of hydrocarbons in volatiles increases, especially the proportion of methane, while the share of some gases such as carbon monoxide (CO) decreases. Also, the hydrogen $\left(\mathrm{H}_{2}\right)$ starts to develop, while the amounts of tar which is produced substantial depend on the lignin and cellulose decompositions in this process stage.

The most interesting for us is the third stage, which takes place in a temperature range of $357.13-800{ }^{\circ} \mathrm{C}$ with weight loss decrease of $27.41 \%$. This high-temperature region corresponds to the polycondensation, the molecular re-arrangement and formation of carbon structure. Our obtained results are in good agreement with approved results reported in the literature that multi-stage pyrolysis process can save $30 \%$ energy and processing time by using a first target temperature about $325{ }^{\circ} \mathrm{C}$ (see above results) and heating rates in the range of $5-10{ }^{\circ} \mathrm{C} \min ^{-1}$ [53]. This strictly corresponds to the appearance of mass loss 
decrease of $27.41 \%$ in a third stage [53]. The black porous solid that remains at the end of pyrolytic process (at the very end of third stage; Fig. 3) comprises mainly the elemental carbon. It should be noted that at identified temperature of $655.29{ }^{\circ} \mathrm{C}$ where strongly exothermic effect occurs (Fig. 3), the transformation of the wood precursor to charcoal reaches its maximum, and then, it is already established. The charcoal at this temperature may still contain appreciable amounts of tar, perhaps $30 \%$ by weight trapped in the structure. This soft burned charcoal needs further heating to drive off more of the tar and thus raise the fixed carbon content of the charcoal to acceptable percent for good quality in commercial purposes. To drive off this tar, the charcoal is subject to further heat inputs to raise its temperature above $T_{\text {sample }}=600{ }^{\circ} \mathrm{C}$, thus completing the carbonization stage. Therefore, this phase and $T_{\text {exo2 }}$ can serve as a reference points for our further study of the pyrolytic behavior in the process that took place in a horizontal tube reactor.

The integrated reaction model parameters for pyrolysis process of untreated plane tree seed sample (Platanus orientalis L.) are shown in Table 2.

It should be notice that the integrated reaction heats expressed through numerically derived dependencies had a very high Adj. $R$-square $\left(R^{2}\right)$ values, especially for Exo2 stage (0.99914) (Table 2). Based on established $R^{2}$, we can conclude that integrated heat model very well describes the real situation, where additional information can be derived from parameter $w_{\mathrm{o}}$ which is part of a complex parameter, $c_{\mathrm{o}}$ (Table 2). Namely, the parameter $w_{\mathrm{o}}$ which is equal to $133.15{ }^{\circ} \mathrm{C}$ describes the active temperature period required for charcoal forming, under the programmed heating mode. The charcoal produced after $655^{\circ} \mathrm{C}$ and above is stable, and in accordance with established fact, we can proceed with further analysis. However, the increasing charcoal yields require minimizing the carbon losses in the form of the gases and liquids and promoting desired pathways, such as primary solid-phase dehydration, decarboxylation and decarbonylation reactions, as well as secondary conversion of the pyrolysis vapors to solids.

\section{Raman spectroscopy results of pyrolyzed sample at $850^{\circ} \mathrm{C}$}

Figure 4 shows Raman spectrum of pyrolyzed sample at $850{ }^{\circ} \mathrm{C}$, where in accordance with the literature, the baseline-corrected Raman curve from 800 to $1800 \mathrm{~cm}^{-1}$ can be peak-fitted with total 7 Gaussian bands. Band intensity or area ratios were usually applied to describe the structure evolution. In this study, the area ratios of some major Raman bands were conducted to investigate the following properties: (i) $A_{\mathrm{G}} / A_{\mathrm{All}}$, band area ratio between $G$ band and all these 7 bands, was used to describe the aromatization extents and (ii) $A_{(\mathrm{VR}+\mathrm{VL}+\mathrm{GR})} / A_{\mathrm{D}}$, band area ratio of the sum of $V_{\mathrm{R}}, V_{\mathrm{L}}$ and $G_{\mathrm{R}}$ bands to the $D$ band, was used to describe the relative content ratio of the smaller aromatic rings to a larger ones [54].

Figure 4 shows that the Raman bands $R, S_{\mathrm{R}}$ and $G_{\mathrm{L}}$ are not present in the spectrum, where these missing bands correspond to $\mathrm{C}-\mathrm{H}$ bond that belongs to aromatic ring (primarily $R$ and $S_{\mathrm{R}}$ bands) and $s p^{2}$ hybridization, at the $\mathrm{C}=\mathrm{O}$ active functional group ( $G_{\mathrm{L}}$ band) [37]. The $G$ band at $1605.45 \mathrm{~cm}^{-1}$ corresponds to aromatic ring quadrant breathing [37]. The $D$ band at $1299.48 \mathrm{~cm}^{-1}$ is primarily referred to medium-to-large-sized aromatic structures (larger than or the equal to six rings systems) [55].

The area between $G$ and $D$ band was curve-fitted with 3 bands, including $G_{\mathrm{R}}\left(1546.36 \mathrm{~cm}^{-1}\right), V_{\mathrm{L}}\left(1455.80 \mathrm{~cm}^{-1}\right)$ and $V_{\mathrm{R}}\left(1366.20 \mathrm{~cm}^{-1}\right)$. These three bands correspond to aromatic structures found in amorphous carbon (with relatively smaller aromatics with 3-5 fused rings) [56].

The maximum peak intensity shows $G$ and $V_{\mathrm{R}}$ bands, but prolonged with $D$ band characterized with greater width and slightly lower intensity. The width of this band is smaller only in the case if nanographite structure is present at higher temperature. However, the latter is not present in obtained product. It should be pointed out that the $G$ band at $1605.45 \mathrm{~cm}^{-1}$ is clearly appeared on the graphite.

The $G$ band is a doubly degenerate (iTO and LO) phonon mode ( $\mathrm{E}_{2 \mathrm{~g}}$ symmetry) at $\mathrm{BZ}$ (Brillouin zone) center that is Raman active for $s p^{2}$ carbon networks. Therefore, since there is a clear $G$ band in the Raman spectrum, we

Table 2 Integrated reaction model parameters [interpolation parameters $a, b, c, a^{*}, b^{*}, c^{*}, a_{\mathrm{o}}, b_{\mathrm{o}}$ and $c_{\mathrm{o}}$ (complex one)] for non-isothermal pyrolysis process of untreated plane tree seed sample (Platanus orientalis L.) involved all reaction stages

\begin{tabular}{lllllllllll}
\hline Stage & Equation & $a$ & $b / \times 10^{-19}$ & $c$ & $a^{*}$ & $b^{* / \times 1 \times 10^{-11}}$ & $c^{*}$ & $a_{\mathrm{o}}$ & $b_{\mathrm{o}}$ & $w_{\mathrm{o}}^{\mathrm{a}}$ \\
\hline Endo & $H=a+b \cdot T^{c}$ & 0.015 & 4.521 & 7.692 & - & - & - & - & - & - \\
Exo1 & $H=\left[a^{*} \cdot b^{*} \cdot T^{\left(1-c^{*}\right)}\right] /\left[1+b^{*} \cdot T^{\left(1-c^{*}\right)}\right]$ & - & - & - & 1.271 & 2.435 & -3.253 & - & - & - \\
Exo2 & $H=a_{\mathrm{o}}+b_{\mathrm{o}} \exp \left[-\exp \left(-c_{\mathrm{o}}\right)-c_{\mathrm{o}}+1\right]^{\mathbf{a}}$ & - & - & - & - & - & - & 0.985 & 1.326 & 133.15 \\
Adj. $R$-square & 0.99812 & & 0.99862 & & 0.99914 & \\
\hline
\end{tabular}

${ }^{\mathrm{a}}$ Complex parameter: $c_{\mathrm{o}}=\left(T_{\text {sample }}-T_{\text {exo } 2}\right) / w_{\mathrm{o}}$, where $w_{\mathrm{o}}$ is expressed in $\left(\mathrm{mg} \mathrm{g}^{-1}\right)$ 


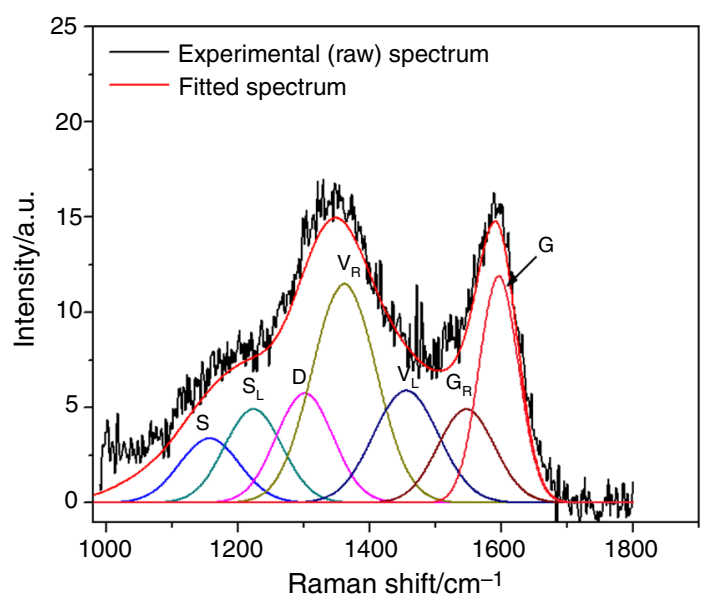

Fig. 4 Curve fitting of the Raman spectrum of pyrolyzed sample at $850{ }^{\circ} \mathrm{C}$

can say that product after pyrolysis contains $s p^{2}$ carbon networks.

Intensity of $G$ band is higher than intensity of $G$ band for a single graphene layer [57], while the FWHM (full width at half maximum) of this band for our sample is a larger than the FWHM of a single graphene layer. The observed feature is the characteristic for the existence of turbostratic graphite, and this is in complete agreement with the obtained XRD results (Fig. 2b).

Intensity of $D$ band can be used to probe the density of defects in the structure, which may lead to the conclusion about the structural defects that can be localized at 2D (two-dimensional) structures. However, the most reports concur that position of $D$ band is related to structural disorder. Strictly, the position of $D$ mode may vary depending on the type of the laser and also of the used wavelength for excitation. Variations in wavelength $\left(\lambda_{\mathrm{o}}\right)$ will change the Raman sampling depth, possibly leading to the variation in the spectrum if the carbon structure varies with depth.

In addition, the intensity ratio $\left(I_{\mathrm{D}} / I_{\mathrm{G}}\right)$ is used as the most useful parameter indicating $s p^{2}$ cluster size. So, the $D$ band indicates disorder in the graphitic structure, but does not necessarily indicate $s p^{3}$ hybridization.

According to Tuinstra and Koenig [58], the ratio of D peak intensity to that of $\mathrm{G}$ peak varied inversely with $L_{\mathrm{a}}$ [where $L_{\mathrm{a}}$ is the cluster size (the cluster diameter)] as $I_{\mathrm{D}} /$ $I_{\mathrm{G}}=C(\lambda) / L_{\mathrm{a}} \quad$ [where $C(\lambda)=532 \mathrm{~nm}$. The following results were obtained: $A_{\mathrm{G}} / A_{\mathrm{All}}=0.16531, A_{(\mathrm{VR}+\mathrm{VL}+\mathrm{GR})} /$ $A_{\mathrm{D}}=4.28848, I_{\mathrm{D}} / I_{\mathrm{G}}=0.48$ and $L_{\mathrm{a}}=1108.33 \mathrm{~nm}$, respectively. The value of $A_{(\mathrm{VR}+\mathrm{VL}+\mathrm{GR})} / A_{\mathrm{D}}$ is quite high indicating a much larger proportion of aromatic rings.

Value $I_{\mathrm{D}} / I_{\mathrm{G}} \sim 0.48$ is much lower than $I_{\mathrm{D}} / I_{\mathrm{G}}$ value (=1.41) for carbons obtained from Limonea acidissima ("wood apple") which is typical for disordered materials such as glassy carbon [47]. Decrease in $I_{\mathrm{D}} / I_{\mathrm{G}}$ indicates the growth of aromatic rings, i.e., the structure of the sample is closer to that of graphite. This result is further supported by the side of the intensities of $D$ and $G$ bands (Fig. 4). Namely, these two bands were attached to disordered behavior ( $D$ band) and graphitic behavior ( $G$ band). Intensity of $G$ band is much greater than the intensity of $D$ band (Fig. 4).

Very high value of $L_{\mathrm{a}}$ may suggest high levels of the growth in basal planes of graphite structure in pyrolyzed sample. This result is in full compliance with a lower value of $I_{\mathrm{D}} / I_{\mathrm{G}}$ ratio. The $S$ band can be considered as a small measure of cross-linking density and substitutional groups (Fig. 4). $B$ and $S_{\mathrm{L}}$ (Fig. 4) can be assigned to contributions from ether- and benzene-related structures. Also, the absence of $G_{\mathrm{L}}$ band in the Raman spectrum indicates outage of carbonyl $\mathrm{C}=\mathrm{O}$ structures, which has previously been indicated. Namely, in pyrolyzed sample, the residual lignin may attend reduction in carbonyl $(\mathrm{C}=\mathrm{O})$ groups and also reduction in aliphatic hydroxyl $(\mathrm{OH})$ structures [59].

\section{GC-MS results}

GC-MS spectra of two raw samples (designated as "raw1" which represents untreated sample and "raw2" represents pulverized sample, respectively) as well as GC-MS spectrum of carbonized (pyrolyzed) sample are shown in Fig. 5a (raw1), b (raw2) and c (pyrolyzed), respectively.

Generally, the detected molecules belong to the group of biogenic compounds, which means that they are synthesized in living systems (such as bacteria, plants, animals). In majority, these are the organic acid esters of long chains (saturated and unsaturated), free organic acids and intermediates of metabolism in living systems. This is particularly evident in the case of "raw1" sample where fatty acids dominates (especially the palmitic acid (Peak 27), the most common fatty acid found in the plants and animals) and expressed fatty acid derivatives (among them, the most common are 9-hexadecen-1-ol (Z)- and 9-octadecenoic acid (Z)-; Peaks 35 and 36) (Fig. 5a) [60, 61]. Identified compounds in all tested samples are presented in Table 3.

In pulverized sample ("raw2"), more extracted chemical compounds were identified compared to untreated sample (Table 3). The mechanical treatment of the sample results in an increase in the number of chemical compounds, where there is a splitting into a more several chemical species.

For carbonized (pyrolyzed) sample, we have the largest abundance of aromatic compounds with a higher numbers of aromatic rings (such as benz[j]aceanthrylen-1-ol, 1,2dihydro-3-methyl-) and then isomeric amines of butane, lactones, etc. (Table 3), and these results are in excellent agreement with previously presented Raman spectrum results. 
Characterization analysis of raw and pyrolyze plane tree seed (Platanus orientalis L.)...

475

Fig. 5 GC-MS spectra of a untreated sample ("r awl"), b pulverized sample ("raw") and c pyrolyze sample, respectively (a)

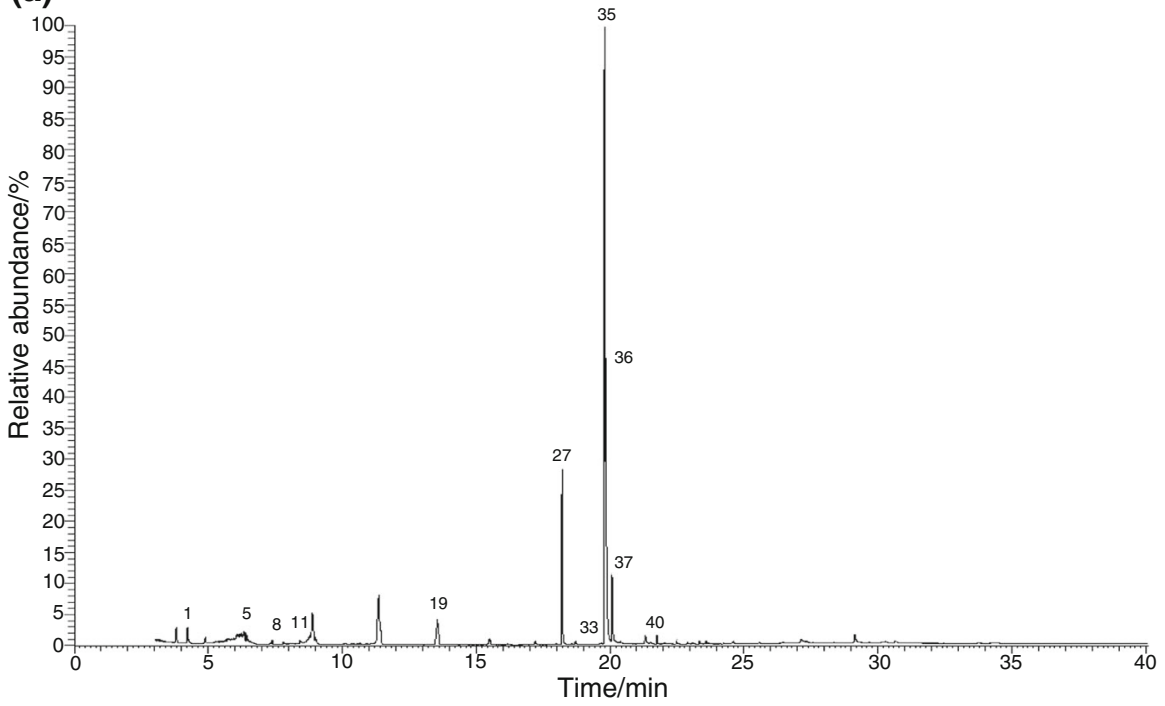

(b)

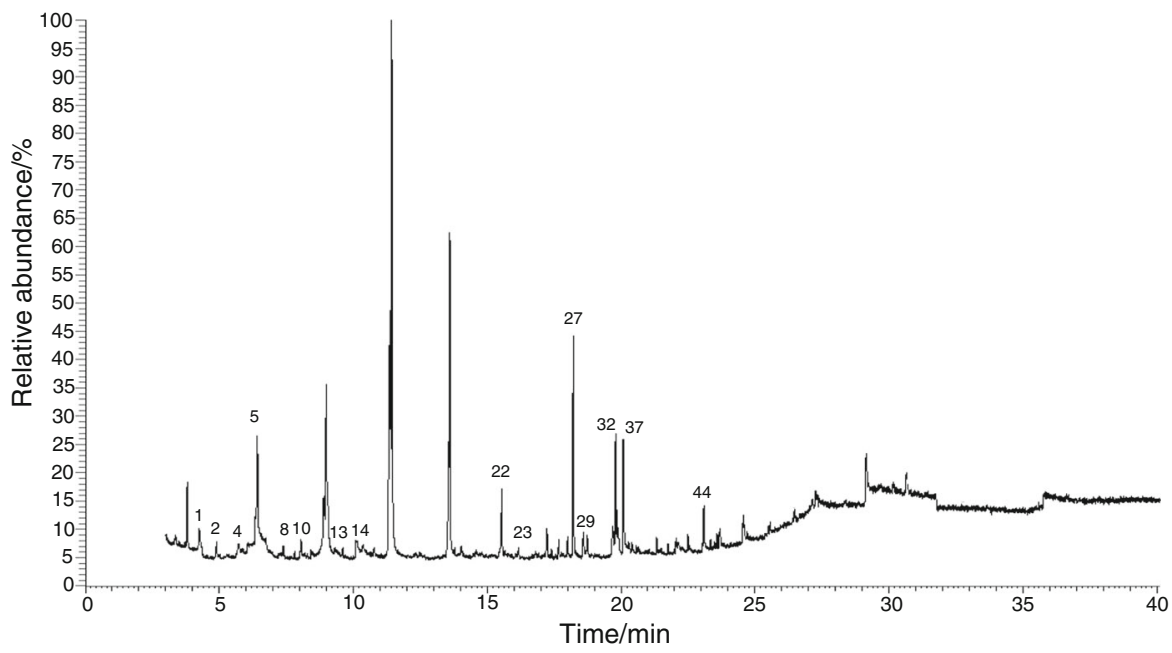

(c)

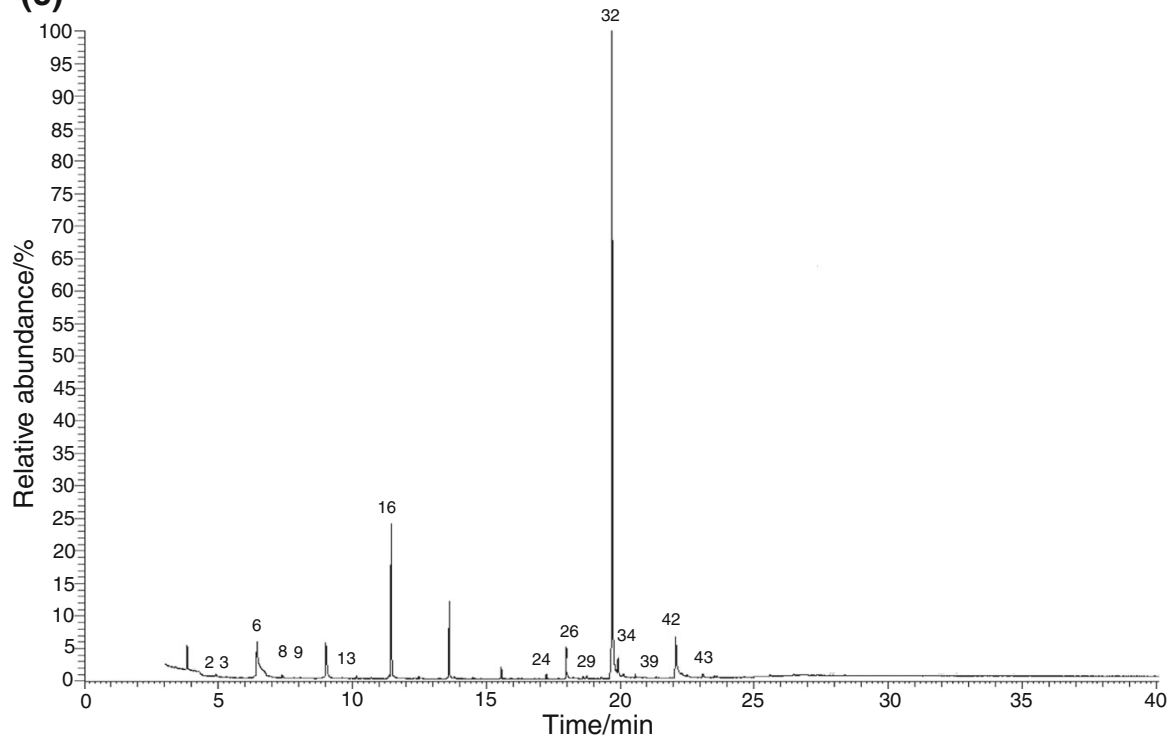

Springer 
Table 3 Systematic overview of 45 compounds identified from GC-MS analysis for "raw1", "raw2" and carbonized (pyrolyzed) plane tree seed samples, respectively

\begin{tabular}{|c|c|c|c|c|c|c|}
\hline Peak No. & $\begin{array}{l}\mathrm{RT}^{\mathrm{a}} \\
/ \mathrm{min}\end{array}$ & Compound & Raw1 & Raw2 & Carbonized & Main/m/z \\
\hline 1 & 4.21 & Benzene, 1-methyl-2,3-dinitro- & + & + & & $165,135,63,52,89$ \\
\hline 2 & 4.91 & 9.10-Anthracenedione, 1 -amino & & + & + & $223,167,195,139$ \\
\hline 3 & 5.28 & 2,4,6-Trimethoxyacetophenone & & & + & $195,210,180$ \\
\hline 4 & 6.08 & Methane, isocyanato- & & + & & $57,28,56,27,55$ \\
\hline 5 & 6.43 & Prednisolone acetate & + & + & & $121,122,43,147$ \\
\hline 6 & 6.48 & Benz[j]aceanthrylen-1-ol, 1,2-dihydro-3-methyl- & & & + & $266,284,267,265,252$ \\
\hline 7 & 7.34 & Gibberellic acid & & & & $121,136,137,152,155$ \\
\hline 8 & 7.40 & Ergoline & + & + & + & $253,254,223,237$ \\
\hline 9 & 7.81 & $\mathrm{~N}$-acethylcolchinol methyl ether & & + & + & $371,312,297,281,254$ \\
\hline 10 & 8.04 & Tridecane & & + & + & $57,43,71,41,85,29,56$ \\
\hline 11 & 8.43 & 7H-Dibenzo(a,g)carbazole, 12,13-dihydro & + & + & & $266,267,268,269,270$ \\
\hline 12 & 9.00 & Ergoline-8-carboxamide, 9,10-didehydro-6-methyl & & & & $267,221,207,180,154,127$ \\
\hline 13 & 9.60 & Nonane & & + & + & $43,57,41,85,71,29,56$ \\
\hline 14 & 10.10 & Benzeneacetaldehyde & & + & & $91,92,120,65$ \\
\hline 15 & 10.68 & Aldosteron & & & & $329,311,283,255,131$ \\
\hline 16 & 11.36 & 1-Butanamine & & & + & $30,73,28,27,41,39$ \\
\hline 17 & 11.44 & Dioxolane & & & & $43,60,71,73$ \\
\hline 18 & 12.47 & Hydrocortisone acetate & & & & $43,41,123,124,163,227$ \\
\hline 19 & 13.52 & 1,3-Dioxolane & + & & & $73,44,29,45,15,43$ \\
\hline 20 & 14.11 & 2-Methoxy-1,3-dioxolane & & & & $45,73,103$ \\
\hline 21 & 14.77 & Benzocaine & & & & $65,92,120,137,165$ \\
\hline 22 & 15.54 & Prednisone & & + & & $121,147,223,255,299,358$ \\
\hline 23 & 16.17 & Tridecanoic acid, methyl ester & & + & & $55,74,87,143$ \\
\hline 24 & 17.20 & Colchicine & & & + & $312,399,297,43,281$ \\
\hline 25 & 17.22 & Bechlomethasone & & & + & $121,147,223$ \\
\hline 26 & 17.96 & Oleyl Alcohol & & & + & $55,82,96,81,67$ \\
\hline 27 & 18.21 & Hexadecanoic acid & + & + & + & $55,74,87,143$ \\
\hline 28 & 18.40 & Benzene, 1,3-bis(1-methylethyl) & & & & $147,119,91$ \\
\hline 29 & 18.59 & Dibutyl phthalate & & + & + & $149,150,41,76,104$ \\
\hline 30 & 18.73 & Propane, 2-methoxy-2-methyl- & & & + & $73,57,41,29,43$ \\
\hline 31 & 19.27 & Oxirane, [[(2-ethylhexyl)oxy]methyl]- & & & + & $57,41,55,43,56$ \\
\hline 32 & 19.60 & 9-Tetradecen-1-ol (E)- & & + & + & $55,41,67,82,81$ \\
\hline 33 & 19.65 & 1,6-Octadien-3-ol, 3,7-dimethyl- & + & & & $71,93,55,43$ \\
\hline 34 & 19.66 & Undecanoic acid, hydroxy-, lactone & & & + & $41,55,29,27,39,42$ \\
\hline 35 & 19.77 & 9-Hexadecen-1-ol (Z)- & + & & & $82,55,41,96,67$ \\
\hline 36 & 19.82 & 9-Octadecenoic acid (Z)-, methyl ester & + & & & $55,69,74,83,97$ \\
\hline 37 & 20.08 & Octadecanoic acid, methyl ester & + & + & & $74,87,43$ \\
\hline 38 & 20.55 & Pentadecylamine & & & + & $30,45,43,44,41$ \\
\hline 39 & 21.36 & 1,3-Dioxolane, 2-heptyl- & & & + & $73,45,41,27,29,74$ \\
\hline 40 & 21.78 & Heptadecanoic acid, methyl ester & + & & & $74,87,43,41,75,55$ \\
\hline 41 & 21.95 & Retinoic acid, methyl ester & & & & $314,105,91,41$ \\
\hline 42 & 22.07 & Oxacyclododecan-2-one & & & + & $41,55,98,69,29,84$ \\
\hline 43 & 23.08 & n-Tridecan-1-ol & & & + & $55,41,43,69,83,56$ \\
\hline 44 & 23.09 & Pentadecane & & + & & $57,43,71,85,41$ \\
\hline 45 & 23.53 & Bis(2-ethylhexyl) phthalate & & & + & $149,167,57,279,71$ \\
\hline
\end{tabular}

${ }^{\mathrm{a}}$ Retention time 

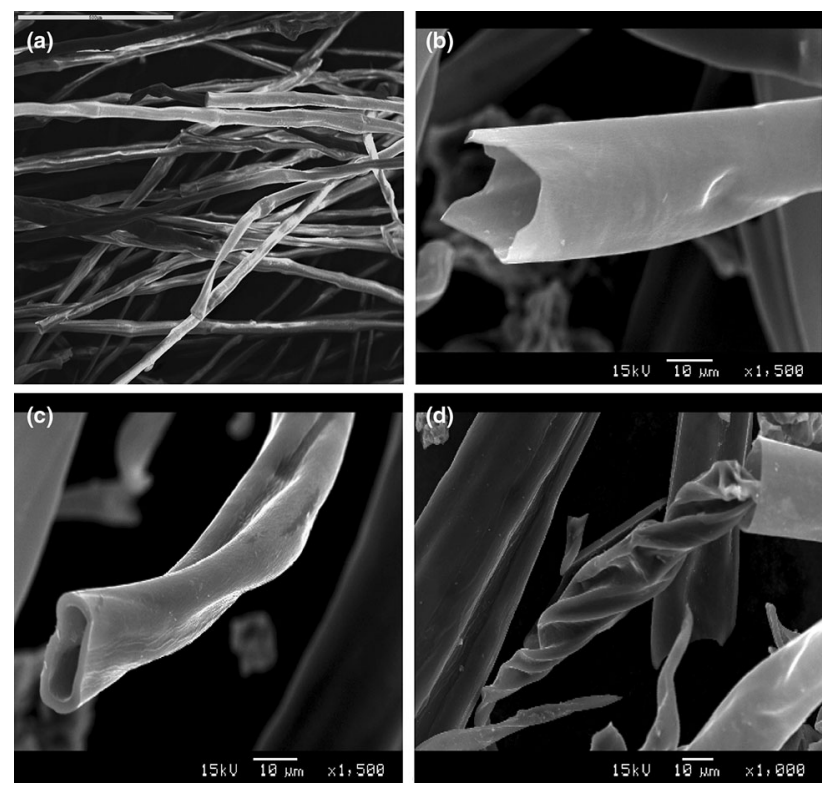

Fig. 6 SEM images of the raw material (PTS) and solid products obtained by pyrolysis process at the fixed operational temperature in a horizontal tube reactor, with high resolutions (raw sample$500 \mu \mathrm{m}, \times 1500$ and $\times 1000$ magnifications)

The aromatics represent a very important group of chemicals, and in this regard at higher temperatures, dehydrogenation/aromatization reactions can eventually lead to the larger polynuclear aromatic hydrocarbons and, eventually, increases in pyrolysis process. So, the general trend is that the higher pyrolysis temperature $\left(850{ }^{\circ} \mathrm{C}\right)$ and longer times enhancing the formation of above detected compounds. It should be noted that this assumption is consistent with lignin pyrolysis mechanism, i.e., the monomolecular dissociation of guaiacols into corresponding radicals (like catechols and cresols) at the higher pyrolysis temperatures. However, the organics subgroup (in the liquid form) consists of organics that are mainly produced during devolatilization, depolymerization and carbonization reactions in the biomass. The knowledge of the composition of volatiles produced in pyrolysis is a topic of interest as it helps in the raw material adaption process, process control, process behavior and operation, energy process and energy optimization, and in the production of green chemicals.

On the other hand, the chemical compounds which contain the oxygen group or an oxygen chemical species are also dominated. Furthermore, the oxygen-containing groups became abundant and they promote the increment of the Raman intensity. This fact can explain increases in $D$ and $G$ bands in Raman spectrum of pyrolyzed sample at $850{ }^{\circ} \mathrm{C}$ (Fig. 4).

Meanwhile, special attention must be given for $\mathrm{CO}_{2}$ interactions with $\mathrm{C}=\mathrm{O}$ group in esters. In this respect, the probable shift effect in the $\mathrm{C}=\mathrm{O}$ stretching frequency may indicate the interactions between gas molecules and polar $\mathrm{C}=\mathrm{O}$ group. The strength of this interaction depends on the binding geometries for $\mathrm{C}=\mathrm{O} \cdots \mathrm{CO}_{2}$ complex, and these structures may differ mainly in the orientation of the gas molecule with respect to the different $R$ groups of the $\mathrm{C}=\mathrm{O}$ containing molecule. In the acetate groups, it is expected that the addition of ester oxygen groups makes the $\mathrm{C}=\mathrm{O}$ oxygen more electron-rich and hence favorable for gas binding. This is very important for capturing the $\mathrm{CO}_{2}$ molecules on the carbonized material and for its further activation in the essential promotion of the selected precursor in the CCS.

\section{SEM results}

Scanning electron microscopy (SEM) technique has been extensively used to qualitatively explore the surface morphology of chars. Surface morphology of solid product obtained after pyrolysis process in a horizontal tube reactor was also investigated in this work, using the SEM technique.

Figure 6 shows the microstructures of the raw plane tree seed (PTS) sample (a) and solid products obtained by carbonization process $(b-d)$ at the fixed operational temperature in a horizontal tube reactor, where all SEM images are presented in high resolutions (for raw sample: $500 \mu \mathrm{m}$, $\times 1000$ and $\times 1500$ magnifications with a resolution of about $10 \mu \mathrm{m})$.

As it can be seen from presented micrographs, the obtained product from plane tree seed pyrolysis shows the variety of structures. We may see that the obtained carbonized solid product contains oval-cracked (Fig. 5b), torsionally twisted (Fig. 5c) and the hollow-twisted (Fig. 5d) tube-shaped structures. These features can be classified within expanded char structure, contrary to flake ones [62]. However, the detected cracks arise from natural behavior of the wood, but also due to the mechanical and thermal stresses. The presence of small clusters can be observed (the central part of Fig. 6c) and in the upper left corner of Fig. 6d), which may be produced from the application of elevated temperatures and formation of highpressure reaction, causing a rapid diffusion of reactant species which contain and carbon atoms. This phenomenon can facilitate that carbon atoms be deposited on some catalyst particle (which may result from the minerals presented in a raw sample). This behavior is quite possible if we take into account the large number of identified aromatic ring structures which may strongly promote this behavior [62]. However, the part of these pores is partially blocked (generally not opened) at some places, which greatly depends on the size of the surface area. In addition, the above observations were consistent with report given 
by Alvarez et al. [63]. It is projected that the degree of structure breakage will increase with higher pyrolysis temperature. In addition, within general case, the carbonized samples show the morphology which is similar to that of raw material (Fig. 6a). Namely, the PTS is made up of fibers of different thickness and shape, and same structure was retained after pyrolysis.

It can be concluded that from the pyrolysis process of raw plane tree seed (PTS) samples, the promising carbonized material can be obtained. Carbonization in itself is relatively not a costly step. Even though retorts may be of high capital cost, they do not require very much labor per unit of production. Typically, the carbonization step may represent about $10 \%$ of total costs from growing and harvesting the tree to arrival of the finished charcoal into the bulk store. The three major factors may affect the conversion yield and they are as follows: (1) moisture content of the wood at time of carbonization, (2) type of carbonizing equipment used and (3) the care with which the process is carried out. Namely, the activation process may result in widening up of the pores. However, the difference in pyrolysis behavior of different biomass materials can result in ultimate chars with different pore structure and porosity. Consequently, the promising precursors such as wood or wood-based materials are being used to produce activated carbon with high surface area, so that wood and wood-based biomasses are still prominent precursors for activated carbon.

In addition, the low-temperature char (below $400{ }^{\circ} \mathrm{C}$ ) was not selected for actual study, because contains volatile matter. The chars produced at higher temperatures (above $400{ }^{\circ} \mathrm{C}$ ) do not contain (or have very low) volatile matter. Therefore, the chosen experimental conditions are adjusted to obtain the char for its conversion into activated carbon. Based on our previously published results [64], it was found that the activated product (through $\mathrm{CO}_{2}$ activation) is characterized by the fine pore structure on the external surface, which may be classified within submicropores that would have crucial role for the gas $\left(\mathrm{CO}_{2}\right)$ sorption. It was found that for $2 \mathrm{~h}$ at $750{ }^{\circ} \mathrm{C}$ and $2 \mathrm{~h}$ at $850{ }^{\circ} \mathrm{C}$ activated samples, the following values of the mesopore surface $\left(S_{\text {meso }}\right)$, the micropore surface $\left(S_{\text {mic }}\right)$ and the total surface areas $\left(S_{\text {tot }}\right)$ were obtained [64]: $S_{\text {meso }}\left(2 \mathrm{~h}: 750{ }^{\circ} \mathrm{C}\right)=47.7$ $\mathrm{m}^{2} \mathrm{~g}^{-1}, S_{\text {mic }}\left(2 \mathrm{~h}: 750{ }^{\circ} \mathrm{C}\right)=526 \mathrm{~m}^{2} \mathrm{~g}^{-1}, S_{\text {tot }}(2 \mathrm{~h}:$ $\left.750{ }^{\circ} \mathrm{C}\right)=573.7 \mathrm{~m}^{2} \mathrm{~g}^{-1}$ and $S_{\text {meso }}\left(2 \mathrm{~h}: 850{ }^{\circ} \mathrm{C}\right)=94.3 \mathrm{~m}^{2}$ $\mathrm{g}^{-1}, S_{\text {mic }}\left(2 \mathrm{~h}: 850{ }^{\circ} \mathrm{C}\right)=610 \mathrm{~m}^{2} \mathrm{~g}^{-1}$ and $S_{\text {tot }}(2 \mathrm{~h}$ : $\left.850{ }^{\circ} \mathrm{C}\right)=704.3 \mathrm{~m}^{2} \mathrm{~g}^{-1}$, respectively. Reported results [64] have been indicated the large surface area (the higher surface areas are probably due to the opening of the restricted pores, as mentioned above) that is available for the adsorption/desorption processes, so clearly represents a big contributor for the high surface area, at elevated activation temperatures. So, taking into account presented results in this work and previously reported results [64], it follows that pyrolysis of PTS throughout elevated thermal treatments shows porosity developing in resulting chars with the meso-microporous structure particles. It was found that BET surface area for PTS activated chars at $850{ }^{\circ} \mathrm{C}$ using low heating rate $\left(704.3 \mathrm{~m}^{2} \mathrm{~g}^{-1}\right)$ is much higher than the same obtained for rice straw, hickory wood, rapeseed bagasse, hornbeam shell, bamboo, apricot stone, hazelnut shell and grape seed, at the higher heating rates [65-68]. This is because, if the heating rate is too high, a higher temperature is reached inside raw material and a partial graphitization with formation of graphene structures occurs. This graphitization is not in favor of the development of a large surface area. So, the higher pyrolysis temperatures and lower heating rates favor the formation of porosity by increasing surface area of chars. It is striking that our result of $704.3 \mathrm{~m}^{2} \mathrm{~g}^{-1}$ surface area for the activated char is a very good result, which promotes PTS as a promising route for its consideration in CCS.

\section{Conclusions}

In this study, the raw and pyrolyzed samples of the plane tree seeds (Platanus orientalis L.) (PTS) were tested by the various analytical techniques. The qualitative and quantitative characteristics of investigated wood precursor and pyrolyzed products were established. From chemical composition analysis, it was found that raw material is the carbon-rich, with cellulose content greater than $30 \%$. FTIR results showed that Platanus orientalis L. raw sample is characterized by the presence of aromatization of sugars structure. The XRD results of raw material have shown that the tested sample is typical for carbon-rich material, with existence of graphite structure. The XRD results of pyrolyzed sample at $850{ }^{\circ} \mathrm{C}$ showed a sudden loss in interlayer spacing. It was established that pyrolyzing temperature strongly affects on the changes in carbon layer interspaces. It has been found that integrated reaction model parameters for pyrolysis process of untreated PTS sample realistically describe the active temperature period required for charcoal forming, under non-isothermal conditions. Raman spectroscopy analysis of pyrolyzed sample showed the presence of typical aromatic structures found in amorphous carbon. The presented results indicate the high levels of the growth in basal planes of graphite structure in pyrolyzed sample. It was found that mechanical treatment of material results in the increase in number of chemical compounds, where there is a splitting into a more several chemical species. GC-MS results for carbonized sample were confirmed the largest abundance of aromatic compounds with a higher numbers of aromatic rings. Based on GC-MS results, aromatic hydrocarbons, aliphatic hydrocarbons, esters, ketones, phenolics, aldehydes and acids can be 
identified as the most prominent organic products. Aromatic hydrocarbons and aliphatic hydrocarbons can be considered as important raw materials in the variety of applications in petrochemical industry, while the phenolics can be considered as the high-added-value chemicals.

Micrographs of obtained product from pyrolysis have been demonstrated a variety of structures. Existence of some dissipated pores was detected. Actual study gives us the opportunity to consider obtained char for its conversion into activated carbon through the thermal conversion processes. Comparing the results of this study with previous reported data, it was concluded that activated material has a large surface area which is available for adsorption/desorption processes. Also, comparing the results of the activated carbon with similar results reported in the literature, it was concluded that PTS and its activated carbons can be taken as promising candidates in the CCS.

Acknowledgements This research work was partially supported by the Serbian Ministry of Education, Science and Technological Development under the projects numbered as 172015 and III45005. The authors would also like to thank Dr. Smilja Marković for taking thermo-analytical measurements on a commercial device.

\section{References}

1. Carapellucci R, Giordano L, Vaccarelli M. The use of biomass to reduce power derating in combined cycle power plants retrofitted with post-combustion $\mathrm{CO}_{2}$ capture. Energy Convers Manag. 2016;107:52-9.

2. Qadir A, Sharma M, Parvareh R, Khalilpour R, Abbas A. Flexible dynamic operation of solar-integrated power plant with solvent based post-combustion carbon capture (PCC) process. Energy Convers Manag. 2015;97:7-19.

3. Oboirien BO, Thulari V, North BC. Enrichment of trace elements in bottom ash from coal oxy-combustion: effect of coal types. Appl Energy. 2016;177:81-6.

4. $\mathrm{Yu} \mathrm{C}-\mathrm{H}$, Huang $\mathrm{C}-\mathrm{H}$, Tan C-S. A review of $\mathrm{CO}_{2}$ capture by absorption and adsorption. Aerosol Air Qual Res. 2012;12:745-69.

5. Scholes CA, Anderson CJ, Stevens GW, Kentish SE. Membrane gas separation-physical solvent absorption combined plant simulations for pre-combustion capture. Energy Proc. 2013;37:1039-49.

6. Mustafa J, Farhan M, Hussain M. $\mathrm{CO}_{2}$ separation from flue gases using different types of membranes. J Membr Sci Technol. 2016;6:153-9.

7. Herzog HJ. The economics of $\mathrm{CO}_{2}$ separation and capture. Cambridge: MIT Energy Laboratory Cambridge; 2000. p. 3-19.

8. Chatterjee S, Rayalu S, Kolev SD, Krupadam RJ. Adsorption of carbon dioxide on naturally occurring solid amino acids. J Environ Chem Eng. 2016;4:3170-6.

9. Wang J, Huang L, Yang R, Zhang Z, Wu J, Gao Y, Wang Q, O'Hare D, Zhong Z. Recent advances in solid sorbents for $\mathrm{CO}_{2}$ capture and new development trends. Energy Environ Sci. 2014;7:3478-518.

10. Hart A, Gnanendran N. Cryogenic $\mathrm{CO}_{2}$ capture in natural gas. Energy Proc. 2009;1:697-706.
11. Zulfiqar S, Sarwar MI, Mecerreyes D. Polymeric ionic liquids for $\mathrm{CO}_{2}$ capture and separation: potential, progress and challenges. Polym Chem. 2015;6:6435-51.

12. Park Y, Andrew Lin K-Y, Allisa Park A-H, Petit C. Recent advances in anhydrous solvents for $\mathrm{CO}_{2}$ capture: ionic liquids, switchable solvents, and nanoparticle organic hybrid materials. Front Energy Res. 2015;3:1-14.

13. Rydén M, Ramos $\mathrm{P} . \mathrm{H}_{2}$ production with $\mathrm{CO}_{2}$ capture by sorption enhanced chemical-looping reforming using $\mathrm{NiO}$ as oxygen carrier and $\mathrm{CaO}$ as $\mathrm{CO}_{2}$ sorbent. Fuel Process Technol. 2012;96:27-36.

14. Duan W, Yu Q. Thermodynamic analysis of hydrogen-enriched syngas generation coupled with in situ $\mathrm{CO}_{2}$ capture using chemical looping gasification method. J Therm Anal Calorim. 2018;131(2):1671-80.

15. Adoption of the Paris agreement-by the President-Draft decision -/CP.21, UNFCCC. 12 December 2015, Archived from the original on 12 December 2015, Retrieved 2015-12-12, Available in Pdf document.

16. Parshetti GK, Chowdhury S, Balasubramanian R. Biomass derived low-cost microporous adsorbents for efficient $\mathrm{CO}_{2}$ capture. Fuel. 2015;148:246-54.

17. Jiménez V, Ramírez-Lucas A, Antonio Díaz J, Sánchez P, Romero A. $\mathrm{CO}_{2}$ capture in different carbon materials. Environ Sci Technol. 2012;46:7407-14.

18. Przepiórski J, Czyżewski A, Pietrzak R, Tryba B. MgO/CaOloaded porous carbons for carbon dioxide capture: effects accompanying regeneration process. $\mathbf{J}$ Therm Anal Calorim. 2013;111(1):357-64.

19. Correia LB, Fiuza RA Jr, de Andrade RC, Andrade HMC. $\mathrm{CO}_{2}$ capture on activated carbons derived from mango fruit (Mangifera indica L) seed shells: a TG study. J Therm Anal Calorim. 2018;131(1):579-86.

20. Vargas DP, Giraldo L, Erto A, Moreno-Piraján JC. Chemical modification of activated carbon monoliths for $\mathrm{CO}_{2}$ adsorption. J Therm Anal Calorim. 2013;114(3):1039-47.

21. Zhong L, Zhang Y, Ji Y, Norris P, Pan W-P. Synthesis of activated carbon from coal pitch for mercury removal in coal-fired power plants. J Therm Anal Calorim. 2016;123(1):851-60.

22. Gül A, Topay M, Özaltın O. The important of urban forests toward to global warming threat. In: International Davraz congress on social and economic issues shaping the world's future: new global dialogue, ISBN 978994445233 5, 24-27 September 2009, Isparta, 2009, pp. 221-234.

23. Rumble H, Rogers K, Doick K, Hutchings T. Valuing Wrexham's urban forests. Assessing the ecosystem services of Wrexham's urban trees: a technical report. The Research Agency of the Forestry Commission, North Wales, Wales, June 2014, 2014, pp. 21-31.

24. Plaza MG, Pevida C, Arias B, Fermoso J, Arenillas A, Rubiera F, Pis JJ. Application of thermogravimetric analysis to the evaluation of aminated solid sorbents for $\mathrm{CO}_{2}$ capture. J Therm Anal Calorim. 2008;92(2):601-6.

25. Bukalak D, Majchrzak-Kucęba I, Nowak W. Assessment of the sorption capacity and regeneration of carbon dioxide sorbents using thermogravimetric methods. J Therm Anal Calorim. 2013;113(1):157-60.

26. ASTM D5373-14e2. Standard Test Methods for Determination of Carbon, Hydrogen and Nitrogen in Analysis Samples of Coal and Carbon in Analysis Samples of Coal and Coke, ASTM International, West Conshohocken, PA, USA, 2014.

27. ISO 1928. Solid Mineral Fuels-Determination of Gross Calorific Value by the Bomb Calorimetric Method and Calculation of Net Calorific Value, USA (standard has been revised by: ISO 1928:2009), 1995. 
28. TAPPI/ANSI T $257 \mathrm{~cm}-12$. Sampling and preparing wood for analysis, Test Method, USA, 2013.

29. T $264 \mathrm{~cm}-97$. Preparation of wood for chemical analysis, Test Method, USA, 2013.

30. Browning BL. Methods of wood chemistry, vol. 2. New York: Interscience Publishers; 1967. p. 561-87.

31. Schoening AG, Johansson G. Absorptiometric determination of acid-soluble lignin in semichemical bisulfite pulps and in some woods and plants. Svensk Papperstid. 1965;68:607-13.

32. TAPPI UM 250. Acid-soluble Lignin in Wood and Pulp, TAPPI Useful Methods, Tappi, Atlanta, GA, USA, 1991.

33. TAPPI T $207 \mathrm{~cm}-99$. Water Solubility of Wood and Pulp, TAPPI Useful Methods, Tappi, Atlanta, GA, USA, 1999.

34. ASTM D1102-84. Standard Test Method for Ash in Wood, ASTM International, West Conshohocken, PA, USA, 2013.

35. Narayan R, Antal MJ. Thermal lag, fusion, and the compensation effect during biomass pyrolysis. Ind Eng Chem Res. 1996;35(5):1711-21.

36. Tarasov A. Thermal analysis: methods, principles, application. lecture on thermal analysis. Lecture series heterogeneous catalysis, FHI MPG, AC FHI Publication, 2012, pp. 1-48.

37. Meng H, Wang S, Chen L, Wu Z, Zhao J. Thermal behavior and the evolution of char structure during co-pyrolysis of platanus wood blends with different rank coals from northern China. Fuel. 2015;158:602-11.

38. El May Y, Jeguirim M, Dorge S, Trouvé G, Said R. Thermogravimetric analysis and kinetic study on palm of phoenix dactylifera L. In: The 7th Mediterranean Combustion Symposium, Chia Laguna, Cagliari, Sardinia, Italy, Sept 11-15, 2011, pp. 1-9.

39. Bendahou A, Dfresne A, Kaddami H, Habibi Y. Isolation and structural characterization of hemicelluloses from palm of Phoenix dactylifera L. Carbohyd Polym. 2007;68:601-8.

40. Strezov V. System approach to biomass pyrolysis: product characterization. In: Din P, Lorenz P, editors. Bionature 2012: The 3rd international conference on bioenvironment, biodiversity and renewable energies, iaria conference. St. Maarten, Netherlands, Antilles, March 25-30, 2012, pp. 7-11.

41. Gu L, Wu S, Li B, Wen H, Zhang D, Ye J, Wang L. Persulfate oxidation assisted hydrochar production from Platanus Orientalis Leaves: physicochemical and combustion characteristics. Biores Technol. 2017;244:517-24.

42. Vhathvarothai N, Ness J, Yu QJ. An investigation of thermal behaviour of biomass and coal during copyrolysis using thermogravimetric analysis. Int J Energy Res. 2014;38:1145-54.

43. Rowell RM, Pettersen R, Tshabalala MA. Cell wall chemistry. In: Rowell RM, editor. Handbook of wood chemistry and wood composites. 2nd ed. Boca Raton: CRC Press; 2013. p. 33-75.

44. Emandi A, Vasiliu CI, Budrugeac P, Stamatin I. Quantitative investigation of wood composition by integrated FT-IR and thermogravimetric methods. Cellulose Chem Tech. 2011;45:579-84.

45. Ejikeme EM, Ejikeme PCN, Abalu BN. Equilibrium, kinetics and thermodynamics studies on MB adsorption using hamburger seed shell activated carbon. Int J Eng Tech. 2014;14:74-83.

46. Assis MR, Brancheriau L, Napoli A, Trugilho PF. Factors affecting the mechanics of carbonized wood: literature review. Wood Sci Technol. 2016;50:519-36.

47. Viswanathan B, Neel PI, Varadarajan TK. Development of carbon materials for energy and environmental applications. Catal Surv Asia. 2009;13:164-83.

48. Hassan MM, Schiermeister L, Staiger MP. Thermal, chemical and morphological properties of carbon fibres derived from chemically pre-treated wool fibres. RSC Adv. 2015;5:55353-62.

49. Lehman JH, Terrones M, Mansfield E, Hurst KE, Meunier V. Evaluating the characteristics of multiwall carbon nanotubes. Carbon. 2011;49:2581-602.
50. Antal MJ, Grønli M. The art, science, and technology of charcoal production. Ind Eng Chem Res. 2003;42:1619-40.

51. Almeida G, Brito JO, Perre P. Alterations in energy properties of eucalyptus wood and bark subjected to torrefaction: the potential of mass loss as a synthetic indicator. Biores Technol. 2010;101:9778-84.

52. Bergman P, Boersma A, Zwart R, Kiel J. Torrefaction for biomass co-firing in existing coal-fired power stations. Energy Research Centre of the Netherlands, Report No. ECN-C-05-013, 2005.

53. Oyedun AO, Lam KL, Hui CW. Charcoal production via multistage pyrolysis. Chin J Chem Eng. 2012;20:455-60.

54. Chu PK, Li L. Characterization of amorphous and nanocrystalline carbon films. Mater Chem Phys. 2006;96:253-77.

55. Zhang S, Min ZH, Tay HL, Asadullah M, Li CZ. Effects of volatile-char interactions on the evolution of char structure during the gasification of Victorian brown coal in steam. Fuel. 2011;90:1529-35.

56. Guo X, Tay HL, Zhang S, Li CZ. Changes in char structure during the gasification of a Victorian brown coal in steam and oxygen at $800 \&$ \#xB0;C. Energy Fuels. 2008;22:4034-8.

57. Ferrari AC, Meyer JC, Scardaci V, Casiraghi C, Lazzeri M, Mauri M, Piscanec S, Jiang D, Novoselov KS, Roth S, Geim AK. Raman spectrum of graphene and graphene layers. Phys Rev Lett. 2006;97:187401.

58. Tuinstra F, Koenig JL. Raman spectrum of graphite. J Chem Phys. 1970;53:1126-30.

59. Lähdetie A. Wood biomass characterization by Raman spectroscopy, school of chemical technology, Department of Forest Products Technology, Aalto University, Doctoral Dissertations, Aalto University publication series, ISBN 978-952-60-5468-1, Helsinki, Finland, 2013, pp. 1-67.

60. Pakdel H, Roy C. Production and characterization of carboxylic acids from wood. Part I: low molecular weight carboxylic acids. Biomass. 1987;13:155-71.

61. Pakdel H, Zhang H-G, Roy C. Production and characterization of carboxylic acids from wood. Part II: High molecular weight fatty acid and resin acids. Biores Technol. 1994;47:45-53.

62. Yan QL, Gozin M, Zhao FQ, Cohen A, Pang SP. Highly energetic compositions based on functionalized carbon nanomaterials. Nanoscale. 2016;8:4799-851.

63. Alvarez J, Amutio M, Lopez G, Nunes J, Olazar M, Bilbao J. Upgrading the rice husk char obtained by flash pyrolysis for the production of amorphous silica and high quality activated carbon. Biores Technol. 2014;170:132-7.

64. Dodevski V, Stojmenović M, Vujković M, Krstić J, Krstić S, Bajuk-Bogdanović D, Kuzmanović B, Kaluđerović B, Mentus S. Complex insight into the charge storage behavior of active carbons obtained by carbonization of the plane tree seed. Electrochim Acta. 2016;222:156-71.

65. Fu P, Hu S, Xiang J, Sun L, Su S, Wang J. Evoluation of the porous structure development of chars from pyrolysis of rice straw: effects of pyrolysis temperature and heating rate. Fuel. 2012;98:177-83.

66. Angin D, Şensöz S. Effect of pyrolysis temperature on chemical and surface properties of biochar of rapeseed (Brassica napus $\mathrm{L}$ ). Int J Phytoremed. 2014;16:684-93.

67. Moralı U, Şensöz S. Pyrolysis of hornbeam shell (Carpinus betulus L.) in a fixed bed reactor: characterization of bio-oil and bio-char. Fuel. 2015;150:672-8.

68. Özçimen D, Ersoy-Meriçboyu A. Characterization of biochar and bio-oil samples obtained from carbonization of various biomass materials. Renew Energy. 2010;35:1319-24. 